\title{
Sun-Shade Plasticity in Leaf Traits of Early and Late-Successional Tree Species in a Low Land Rain Forest South West Sri Lanka
}

Batuwatta S.*and Singhakumara B.M.P.

Department of Forestry and Environmental Science, Faculy of Applied Sciences, University of Sri Jayawardenepura, Nugegoda, Sri Lanka.

*sonalibatuwatta@yahoo.com

\begin{abstract}
Light is one of the most limiting resources for plant growth and survival in lowland rain forests. Leaf morphology and leaf chemical characteristics have proven to be important features that adjust continuously to the changing light environment. The objective of the study was to investigate the plasticity of leaf traits of early and late-successional species, and to compare the plasticity differences in leaf traits of sun and shade leaves of these two groups. Ten species were selected for the study: five early-successional species; Alastonia macrophylla, Trema orientalis, Macaranga peltata, Wendlandia bicuspidate and Schumacheria castaneifolia and five late-successional species; Shorea congestiflora, Mesua nagassarium, Dipterocarpus zeylanicus, Shorea disticha and Shorea cordifolia.
\end{abstract}

Sun and shade leaves of fully matured trees were collected from three sample locations. Measured chemical attributes are leaf nutrients (leaf Nitrogen and Phosphorus) and leaf chlorophyll content. Chlorophyll: Nitrogen ratio was calculated using these values. Measured morphological attributes are leaf length, leaf width, leaf area, and leaf dry /fresh weight and derived parameters are leaf dry matter content and specific leaf area. Leaf trait plasticity was calculated for each species based on the mean leaf trait values in the sun and shade.

Most of the leaf chemical and morphological characteristics varied between sun and shade leaves of early and late successional groups. Specific leaf area was higher in shade leaves than sun leaves $(\mathrm{p}>0.05)$. In early- successional species, leaf trait plasticity was higher in specific leaf area (19\%), Nitrogen content (23\%), Phosphorus content (31\%) and it was relatively low in leaf area $(5.7 \%)$, leaf length $(4.2 \%)$ and leaf width $(4.6 \%)$. In latesuccessional species, leaf trait plasticity was higher in specific leaf area (10.3\%), Nitrogen content $(16.4 \%)$ and Phosphorus content $(21 \%)$ and plasticity was relatively low in leaf area $(3.5 \%)$ and leaf length (4\%).Early -successional species have shown a higher plasticity than late-successional species.

Keywords: Low land rain forest, Irradiance, Plasticity, Sun-Shade leaves, Leaf morphology characteristics, Leaf chemical characteristics 